June 16, 2007

\title{
Measurement and Interpretation of Seismic Attenuation for Hydrocarbon Exploration
}

Grant/Cooperative Agreement DE-FC26-04NT15505.

FINAL REPORT

Report Period Start Date: January 1, 2005

Report period End Date: June 30, 2007

Primary Author: Dr. Michael Batzle

Prime Contractor: Colorado school of Mines

Department of Geophysics

1500 Illinois St.

Golden, Colorado 80401

Subcontractors: $\quad$ University of California, Berkeley

Associated

Research Institution: Lawrence Berkeley National Laboratory

Industrial Collaborator: Chevron Corporation

Principal Investigators:

M. Batzle - Colorado School of Mines

Luca Duranti - Chevron Corporation

James Rector - University of California

Steve Pride - Lawrence Berkeley National Laboratory 


\section{Disclaimer:}

This report was prepared as an account of work sponsored by an agency of the United States Government. Neither the United States Government nor any agency thereof, nor any of their employees, makes any warranty, express or implied, or assumes any legal liability or responsibility for the accuracy, completeness, or usefulness of any information, apparatus, product, or process disclosed, or represents that its use would not infringe privately owned rights. Reference herein to any specific commercial product, process, or service by trade name, trademark, manufacturer, or otherwise does not necessarily constitute or imply its endorsement, recommendation, or favoring by the United States Government or any agency thereof. The views and opinions of authors expressed herein do not necessarily state or reflect those of the United States Government or any agency thereof. 


\begin{abstract}
$\underline{\text { Abstract: }}$
This research project is the combined effort of several leading research groups. Advanced theoretical work is being conducted at the Lawrence Berkeley National Laboratory. Here, the fundamental controls on loss mechanisms are being examined, primarily by use of numerical models of heterogeneous porous media. At the University of California, Berkeley, forward modeling is combined with direct measurement of attenuation. This forward modeling provides an estimate of the influence of 1/Q on the observed seismic signature. Direct measures of losses in Vertical Seismic Profiles (VSPs) indicate mechanisms to separate scattering versus intrinsic losses. At the Colorado School of Mines, low frequency attenuation measurements are combined with geologic models of deep water sands. ChevronTexaco is our corporate cosponsor and research partner. This corporation is providing field data over the Genesis Field, Gulf of Mexico. In addition, ChevronTexaco has rebuilt and improved their low frequency measurement system. Soft samples representative of the Genesis Field can now be measured for velocities and attenuations under reservoir conditions.

Throughout this project we have:

- Assessed the contribution of mechanical compaction on time-lapse monitoring

- Developed and tested finite difference code to model dispersion and attenuation

- Heterogeneous porous materials were modeled and 1/Q calculated vs. frequency

- 'Self-affine' heterogeneous materials with differing Hurst exponent modeled

- Laboratory confirmation was made of meso-scale fluid motion influence on 1/Q

- Confirmed theory and magnitude of layer-based scattering attenuation at Genesis and at a shallow site in California.

- Scattering Q's of between 40 and 80 were obtained

- Measured very low intrinsic Q's (2-20) in a partially saturated vadose zone VSP.

- First field study to separate scattering and intrinsic attenuation in real data set.

- Revitalized low frequency device at ChevronTexaco's Richmond lab completed

- First complete frequency dependent measurements on Berea sandstones from dry to various saturations (brine and decane).

- Frequency dependent forward modeling code is running, and tested on a couple of

Cases: derives frequency dependent reflectivity from porosity based logs.

- Genesis seismic data obtained but is on hold until forward modeling is complete.

- Boundary and end effects modeled for soft material measurements at CSM

- Numerous papers published or submitted and presentations made.
\end{abstract}




\section{Contents:}

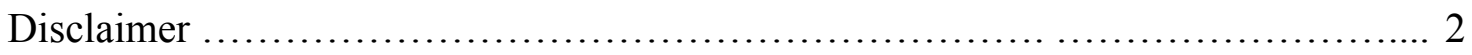

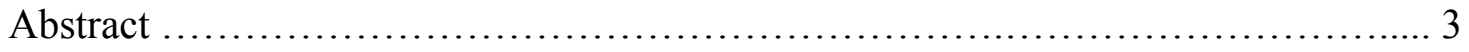

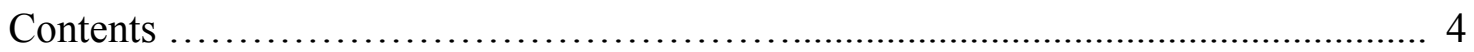

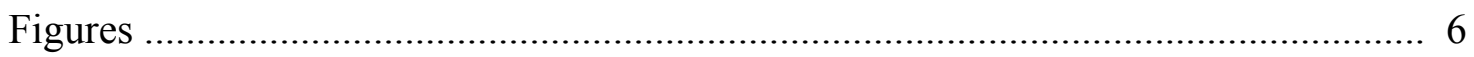

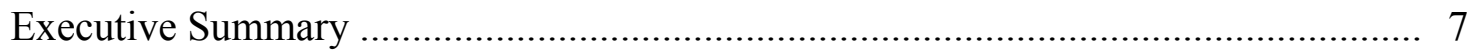

Results and Discussion .............................................................. 9

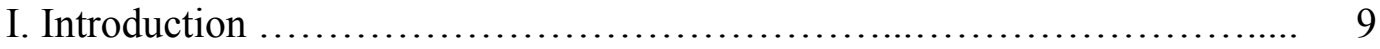

II. Activity at Chevron................................................................... 11

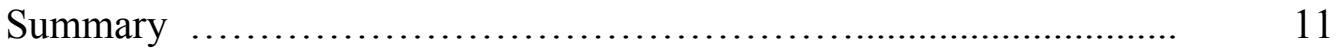

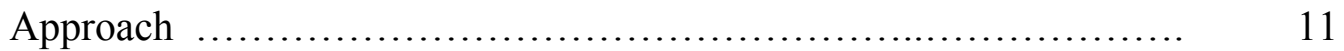

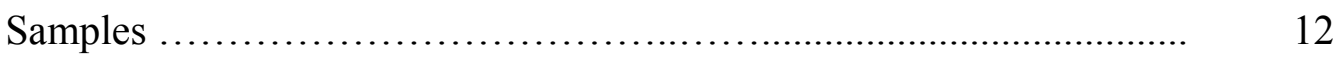

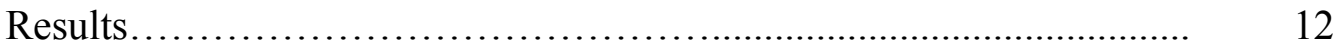

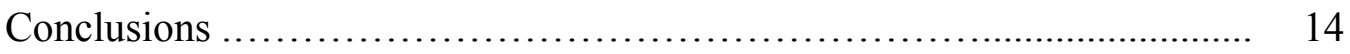

III. Activity at the Colorado School of Mines ......................................... 19

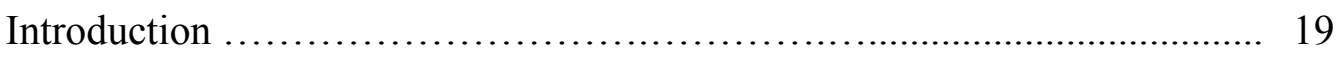

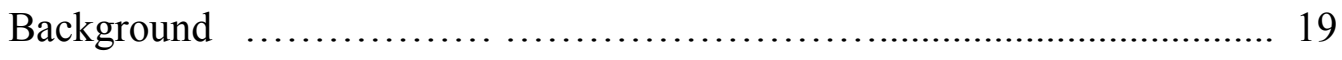

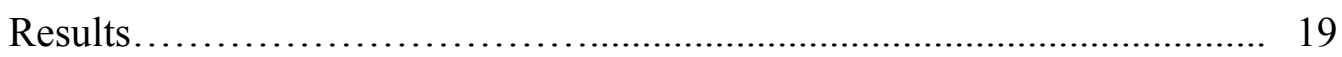

IV. Activity at Lawrence Berkeley National Laboratory .................................. 23

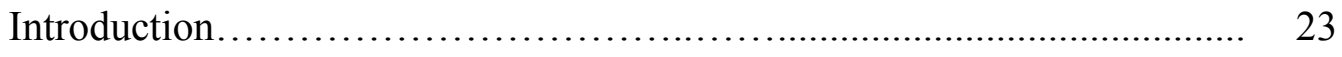

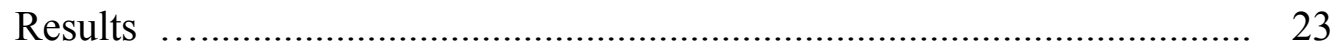


V. Activity at the University of California, Berkeley............................... 27

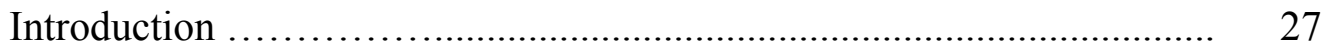

Data Acquisition .................................................................................... 27

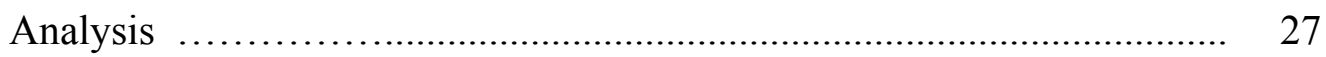

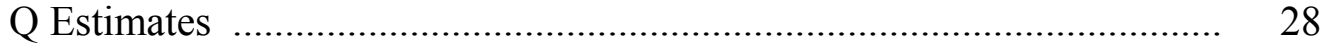

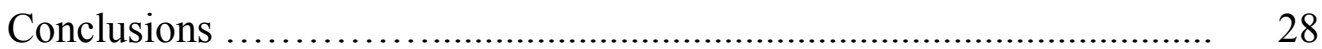

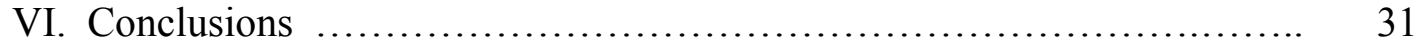

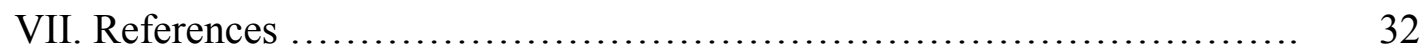




\section{Figures:}

Figure 1. Young's modulus of dry Berea Sandstone $\ldots \ldots \ldots \ldots \ldots \ldots \ldots \ldots \ldots \ldots \ldots \ldots$

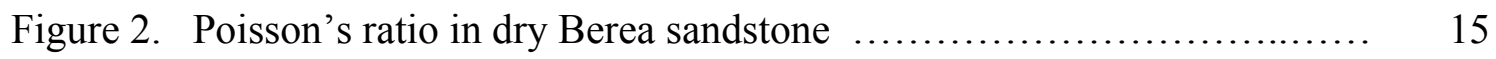

Figure 3. P-wave attenuation in dry Berea sandstone at four confining pressures... 16

Figure 4. P-wave attenuation in water-saturated Berea sandstone $\ldots \ldots \ldots \ldots \ldots \ldots . . \ldots$

Figure 5. Shear modulus in water-saturated Berea sandstone .......................... 17

Figure 6. Bulk modulus in water-saturated Berea sandstone............................. 17

Figure 7. Erratic bulk modulus in water-saturated Berea sandstone $\ldots \ldots \ldots \ldots \ldots . .18$

Figure 8. Lateral gages show inhomogeneous deformation ............................. 20

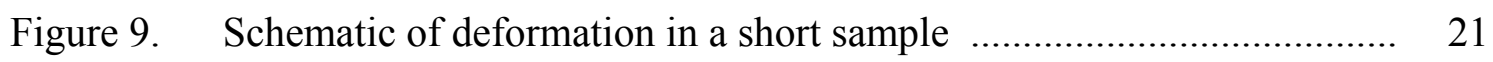

Figure 10. Geometries involved in soft sample deformation $\ldots \ldots \ldots \ldots \ldots \ldots \ldots \ldots \ldots . . . . \ldots \ldots$

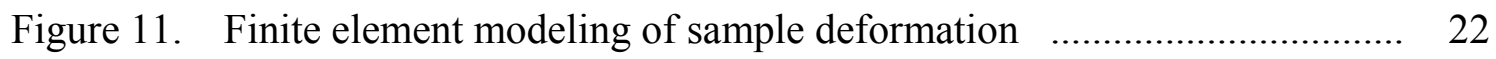

Figure 12. Geometries of the samples used to test the dual porosity theory ....... 24

Figure 13. Realmodulus and 1/Q obtained from the samples in Figure 12 ........ 25

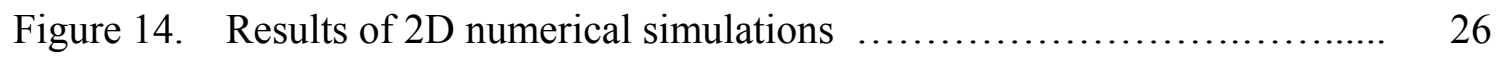

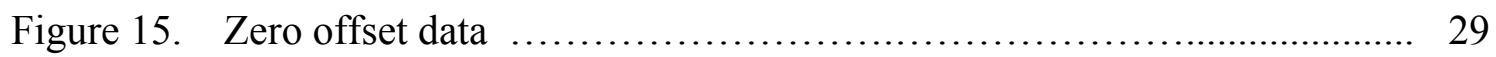

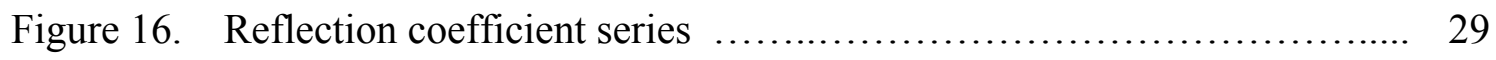

Figure 17. Relative amplitudes of synthetic and real data $\ldots \ldots \ldots \ldots \ldots \ldots \ldots \ldots . . \ldots$ 


\section{Executive Summary:}

Exploring for and developing hydrocarbon reservoirs are risky and expensive. This is particularly true for deep water targets. Seismic attenuation (1/Q) can help both in identifying the original pore fluid type and in monitoring reservoir production. Current seismic technology has difficulty distinguishing between economic gas reservoirs and uneconomic reservoirs with partial gas saturation. 1/Q could prove an available seismic attribute allowing hydrocarbon saturations to be estimated

The focus of this research is to help advance our use of seismic attenuation (1/Q) data to directly detect hydrocarbons and evaluate the in situ saturations. Numerous seismic Direct Hydrocarbon Indicators (DHI's) are in use and many more have been suggested. However, many of these indicators yield ambiguous results at best. Because of the direct tie between seismic attenuation and fluid content, 1/Q has always been suggested as a potential hydrocarbon indicator. Our approach is to both develop new methods to ascertain in situ 1/Q as well as to constrain dominant loss mechanism and calibrating extraction techniques.

In this research project, we are combining the efforts of several leading research groups. Advanced theoretical work is being conducted at the Lawrence Berkeley National Laboratory. Here, the fundamental controls on loss mechanisms are being examined, primarily by use of numerical models of heterogeneous porous media. At the University of California, Berkeley, forward modeling is combined with direct measurement of attenuation. This forward modeling provides an estimate of the influence of 1/Q on the observed seismic signature. Direct measures of losses in Vertical Seismic Profiles (VSPs) indicate mechanisms to separate scattering versus intrinsic losses. At the Colorado School of Mines, low frequency attenuation measurements are combined with geologic models of deep water sands. ChevronTexaco is our corporate cosponsor and research partner. This corporation is providing field data over the Genesis Field, Gulf of Mexico. In addition, ChevronTexaco has rebuilt and improved their low frequency measurement system. Soft samples representative of the Genesis Field can now be measured for velocities and attenuations under reservoir conditions.

During this project:

- Finite difference code developed to model porous media dispersion and attenuation

- Code tested against analytical solutions

- Heterogeneous porous materials (i.e. rocks) modeled and 1/Q calculated vs. frequency

- 'Self-affine' heterogeneous materials with differing Hurst exponent modeled

- Laboratory confirmation of meso-scale fluid motion influence on 1/Q

- Geomechanical models are applied to Genesis data to estimate effect of compaction

- Compaction effects due to pore pressure withdrawal tested in the laboratory

- Confirmed theory and magnitude of layer-based scattering attenuation at Genesis and at a shallow site in California.

- Scattering Q's of between 40 and 80 were obtained 
- Measured very low intrinsic Q's (2-20) in a partially saturated vadose zone VSP.

- First field study to separate scattering and intrinsic attenuation in real data set.

- Revitalized low frequency device at ChevronTexaco's Richmond lab finally installed 2 pore fluid ports for LFQ device with valves obtained and tested seamless jacketing material over epoxy coat Results are excellent (so far).

- First complete frequency dependent measurements on Berea sandstones from dry to various saturations (brine and decane).

- Duplicated CSM's results on frequency dependence (but smaller freq. band: 1 - $500 \mathrm{~Hz}$ ).

- Boundary and end effects were modeled at CSM and tested against data

- Sample selection of a complete set of clean (practically no clay) sandstones and sands

(unconsolidated) for low frequency device at ChevronTexaco and CSM.

Porosity from $14 \%$ to $32 \%$, every $2 \%$.

- Frequency dependent forward modeling code is running, and tested on a couple of

Cases: derives frequency dependent reflectivity from porosity based logs.

- Genesis seismic data obtained but is on hold until forward modeling is complete.

- Numerous papers and presentations have been produced as a result of this project 


\section{$\underline{\text { Results and Discussion }}$}

\section{Introduction}

Seismic attenuation measurements have long been proposed as a method to identify fluids or zones of high permeability in situ. Field data is now improving to the point where qualitative estimates of 1/Q are possible, based largely on frequency content. However, interpretation is still hampered by a lack of understanding of the primary mechanisms involved in intrinsic $1 / \mathrm{Q}$. Direct observation of loss and dispersion within the seismic frequency band in the laboratory point toward several independent, competing mechanisms. Theoretical modeling of the mechanisms allows us to extend and apply these measured results to general in situ conditions.

This research project strives to improve not only our understanding of attenuation, but also to develop and test techniques that allow us to extract estimates of 1/Q from field seismic data. This goal requires the integration of several disciplines. Hence, this project is a collaborative effort among Chevron Corporation, the Colorado School of Mines, Lawrence Berkeley National Laboratory, and University of California at Berkeley. We will summarize the results of each of these research partners in turn below.

One of the primary responsibilities of this project is also to disseminate the results of this research to the technical and commercial communities. To fulfill this requirement, numerous publications and public presentations have been made. A list of the publications sponsored, at least in part, by this research grant include:

Ruiz, Begoña, Comparison of Measured and Modeled Frequency Dependent Moduli in Sandstones: PROCEEDINGS, Rainbow in the Earth $-2^{\text {nd }}$ International Workshop Lawrence Berkeley National Laboratory, Berkeley, California, August 17-18, 2005.

Pride, S.R. (2005), Relationships between seismic and hydrological properties, in Ilydrogeo- physics, edited by Y. Rubin and S. Hubbaxd, pp. 253-291, Chapter 9, Springer, New York.

Duranti, L., Ewy, R., and Hofmann, R., Dispersive and Attenuative Nature of Shales: Multiscale and Multifrequency Observations: Society of Exploration Geophysicists Annual Technical Meeting, 2005.

Batzle, M., Hofmann, R., Prasad, M., Gautam, K., Duranti, L., and Han, D-h., Seismic Attenuation: Observations and Mechanisms: Society of Exploration Geophysicists Annual Technical Meeting, 2005. 
Masson, Y.J., S.R. Pride and K.T. Nibei (2006), Finite difference modeling of Biot's poroelastic equations at seismic frequencies. J. Geophys. Res., 111, B10305, 13 pages.

Pride, S.R. and Y.J. Masson (2006), Acoustic attenuation in self-affine porous structures. Phys. Rev. Lett., 97, 184301.

Masson, Y.R. and S.R. Pride (2007), Poroelastic finite-differeince modeling of seismic attenuation and dispersion due to mesoseopic-scale heterogeneity, J. Geophys. Res., 112, to appear in February/March issue.

Gautam Kumar, M. Batzle, Ronny Hofmann (2007), Seismic Attenuation: Influence of Macroscopic Fluid Flow; in review, Geophysical Prospecting. 


\section{Activity at Chevron}

\section{$\underline{\text { Summary }}$}

We have successfully measured two complex elastic moduli (Young's modulus and Poisson's ratio) in dry and water-saturated Berea sandstone under confining pressures to 2000 psi $(13.79 \mathrm{MPa}$ ) at frequencies from 0.2 and $200 \mathrm{~Hz}$. With two complex moduli, and assuming the material is homogeneous and isotropic, we can calculate the P-wave, bulk and shear moduli, as well as the P- and S-wave attenuations. As would be expected, the results show large increases in the elastic moduli and steady reductions in the attenuations with increasing confining pressure, which are attributed to the closure of microcracks and the stiffening of grain contacts. As expected, the shear attenuation is greater than the $\mathrm{P}$-wave attenuation. At 2000 psi, the P-wave attenuation (1/Q $\mathrm{Q}_{\mathrm{P}}$ ) in dry Berea is only $0.001+/-0.001$ (or $\mathrm{Q}_{\mathrm{P}}$ is over 500). Following an approach developed by Mike Batzle and coworkers at Colorado School of Mines (Batzle et al., 2005), we implemented an electrically-activated, pore fluid valve that enables measurements on saturated samples under both closed and drained pore-fluid conditions. Our results, using another low-frequency apparatus, duplicate the behavior seen in the School of Mines experiments. When the pore fluid valve is closed, we are measuring the desired water-saturated moduli, and $\mathrm{Q}_{\mathrm{P}}$ is near 250 at only 1000 psi differential pressure. In contrast, when the pore fluid valve is opened, there is strong dispersion in the bulk modulus (and a large attenuation peak) because at low to intermediate frequencies the dynamic pore water pressure is relaxing to the relatively large volume inside the body of the pore-fluid valve. This creates what is called a "drained pore-fluid condition", following the terminology used in soil mechanics testing. The sample remains fully-saturated but, at low frequencies below several Hertz, the water-saturated sample behaves as if it were partiallysaturated. The sample behavior is reversible by opening and closing the pore fluid valve.

\section{Approach}

Under the outline of the DOE Attenuation Project, Chevron agreed to use their lowfrequency apparatus, previously described by Spencer et al. (1994), to measure moduli and attenuations in samples of Berea sandstone and unconsolidated reservoir sands from the Genesis Field. The agreed upon approach was for the Colorado School of Mines (CSM) and Chevron to make comparison measurements on dry and water-saturated Berea sandstone, and then for Chevron to analyze the unconsolidated Genesis samples. This division of effort was because the CSM apparatus (which requires strain gages to be cemented to the sample) cannot measure unconsolidated sands.

While Chevron's low-frequency apparatus was initially developed to study attenuation (Spencer, 1981), after the problem of pore fluid relaxation to the free surface was recognized [White (1985) and Dunn (1987)], the emphasis of the laboratory research and apparatus development changed to measuring the frame moduli of unconsolidated sands. During the 
major apparatus development in the late 1980's, little attention was paid to the six phase angle measurements that would be needed calculate attenuation values. For the current measurements of moduli and attenuations, we had to go back and solve electricalinterference problems that were giving erroneous phase values (and to a lesser extent amplitudes) that depended on the signal levels. The results herein show that this effort was successful.

\section{$\underline{\text { Samples }}$}

For the comparison measurements at CSM and Chevron, Chevron prepared adjacent samples from the same block of Berea sandstone. The sample analyzed by Chevron was 1.5 inches $(3.83 \mathrm{~cm})$ in diameter and approximately 4.25 inches $(10.8 \mathrm{~cm})$ in length. As agreed upon by Ronny Hofmann (CSM) and Spencer, for a reproducible dry condition, samples were allowed to equilibrate in a room-temperature vacuum oven for at least 48 hours before jacketing. Chevron samples are jacketed in heat-shrink mylar tubing and then painted with a flexible, conductive coating that serves as the target for the capacitive radial displacement sensors. The sample analyzed by Chevron had a dry bulk density of $2.006 \mathrm{~g} / \mathrm{cm} 3$, which gives a calculated porosity of 24.3 percent (assuming grain density $=2.65 \mathrm{~g} / \mathrm{cm} 3$ ).

\section{$\underline{\text { Results }}$}

\section{Dry Berea Sandstone}

We initially measured two complex elastic moduli (Young's modulus and Poisson's ratio) in dry Berea sandstone under confining pressures to $2000 \mathrm{psi}(13.79 \mathrm{MPa})$ at frequencies from 0.2 and $200 \mathrm{~Hz}$. Hofmann and Spencer agreed on the sequence of confining pressures (500, 1000 and 2000 psi) so as to cover the range of interesting rock behavior without "pushing" the capability of either apparatus. With two complex moduli, and assuming the material is homogeneous and isotropic, we can calculate the P-wave, bulk and shear moduli, as well as the P- and S-wave attenuations. As would be expected, the dry results (see Figures 1-3) show there are large increases in the Young's modulus and steady reductions in the P-wave attenuation with increasing confining pressure, which are attributed to the closure of microcracks and the stiffening of grain contacts. The small amount of scatter in the Young's modulus measurements is caused by minor time-dependent stiffening of the sample during multiple frequency sweeps. After accounting for the time-dependent stiffening, there is weak modulus dispersion that is approximately linear in log (frequency). As expected in a dry sandstone, the shear attenuation (not shown) is somewhat greater than the P-wave attenuation. At $2000 \mathrm{psi}$, the $\mathrm{P}$-wave attenuation $\left(\mathrm{QP}^{\wedge}-1\right)$ in dry Berea is only $0.001+/-$ 0.001 (or QP is over 500). 


\section{Electrically-Activated Valve for Control of Pore-fluid Condition}

Over the last ten years, Batzle and coworkers have shown that they can eliminate the problem of pore fluid relaxation to the free surface of the sample by painting the surface of the sample with a thin layer of Cytec Industries' K-20 epoxy and then applying a jacket of Kapton film . After sealing the outer surface of the sample, the CSM group [Batzle et al. (2005)] uses a "micro-valve" to control fluid movement in and out of the sample, and whether the sample's pore space is open or closed. Their "micro-valve" consists of an inverted cone seal on a stiff wire that passes through the pressure vessel head, and can be manipulated remotely. For safety reasons and greater ease of use, we decided to instead use an electrically-activated solenoid valve (Peter Paul Electronics \#52J8DGB) operating inside the nitrogen-medium pressure vessel and positioned as close as possible to the top of the sample. We modified a standard \$35 valve by welding input and output fittings to the valve body, and then welding the valve body and sleeve assembly together to eliminate any leaks. Peter Paul Electronics recently began offering essentially the same modification as a commercial product (for a photograph, see http://www.peterpaul.com/latest-press-releasesdisplay.php? $\mathrm{id}=26 \& \mathrm{cat} \mathrm{id}=3$ ). The only other "trick" was reversing the valve so there is minimal dead volume on the side of the valve that is connected (using a short length of capillary tubing) to the sample. In this way, when the valve is opened, the dynamic pore fluid pressure can relax into the relatively large volume of the valve body, thus creating a drained pore-fluid condition at low frequencies.

Water-saturated Berea Sandstone

Figure 4 shows the P-wave attenuation in water-saturated Berea sandstone under closed versus drained pore-fluid conditions. The behavior is reversible by opening and closing the pore fluid valve. There is strong $\mathrm{P}$-wave attenuation in the drained pore-fluid condition which is caused by bulk relaxation of the dynamic pore water pressure to the relatively large volume inside the body of the pore-fluid valve. In this and subsequent figures, "N2 gas" refers to the presence of a free nitrogen gas phase in the pore space after the jacket began

leaking Figure 5 shows the shear modulus data in water-saturated Berea sandstone under closed and drained pore-fluid conditions. Comparison of the dry and water-saturated data at 1000 psi shows that there is a water-softening effect. As would be expected, there are negligible differences between the measured shear moduli under closed and drained porefluid conditions.

Figure 6 shows the corresponding bulk modulus data under closed and drained pore-fluid conditions. The behavior is reversible by opening and closing the pore fluid valve. At low frequencies below several Hertz, there is close agreement between the dry frame bulk modulus and the bulk modulus with the pore fluid valve open. Anomalous results were observed at high frequencies where the drained bulk moduli (with valve open) are uniformly larger than the saturated bulk moduli measured with the valve closed. Figure 7 shows other erratic bulk modulus data measured on the same sample with the pore-fluid valve open, but 
with different pore fluid pressures. The complicated, frequency-dependent behavior suggests that there is a complex resonance and anti-resonance behavior in the pore-fluid valve which is causing the anomalous bulk modulus values shown in Figure 6. This measurement artifact has limited practical importance because we will normally be using the fluid-saturated data measured with the valve closed. We will only use the open-valve data for (1) confirming that the sample is fully saturated, and (2) determining the low-frequency, drained-frame moduli.

\section{Conclusions}

We have improved Chevron's low-frequency apparatus so it can reliably measure two complex elastic moduli (Young's modulus and Poisson's ratio). With two complex moduli, and assuming the material is homogeneous and isotropic, we can calculate the P-wave, bulk and shear moduli, as well as the P- and S-wave attenuations. At 2000 psi, the P-wave attenuation $\left(\mathrm{QP}^{\wedge}-1\right) \mathrm{QP}$ in dry Berea sandstone is only $0.001+/-0.001$ (or QP is over 500 ). Following the approach developed by Batzle and coworkers, we have implemented an electrically-activated, pore fluid valve that enables measurements on fluid-saturated samples under both closed and drained pore-fluid conditions. Our results, using another lowfrequency apparatus, duplicate the behavior seen in Batzle and coworkers' experiments. With the pore fluid valve closed, we are measuring the desired water-saturated moduli and attenuations. The QP of water-saturated Berea sandstone is near 250 at only $1000 \mathrm{psi}$ differential pressure. A qualitative comparison between recent CSM data (Adam et al., 2006) and Chevron data herein suggests that the capacitive displacement sensors in Chevron's apparatus are giving "cleaner" (higher $\mathrm{S} / \mathrm{N}$ ratio) data than the strain gages used in the CSM apparatus. 


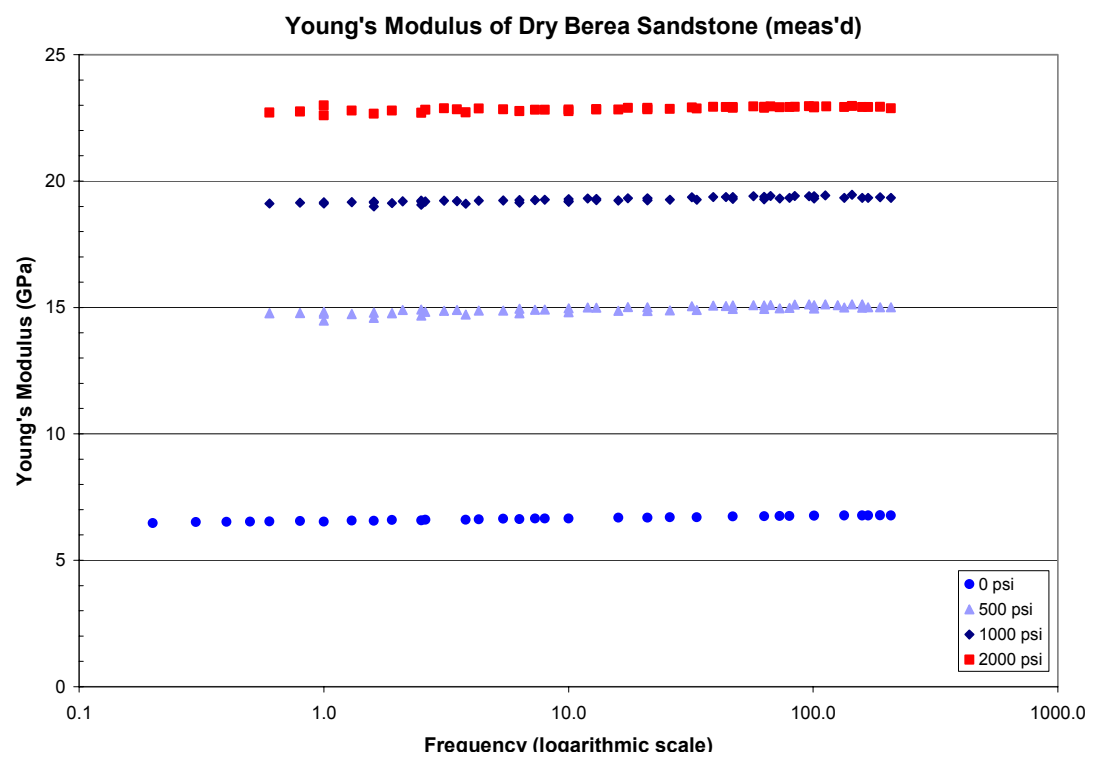

Figure 1. Young's modulus of dry Berea sandstone at four confining pressures.

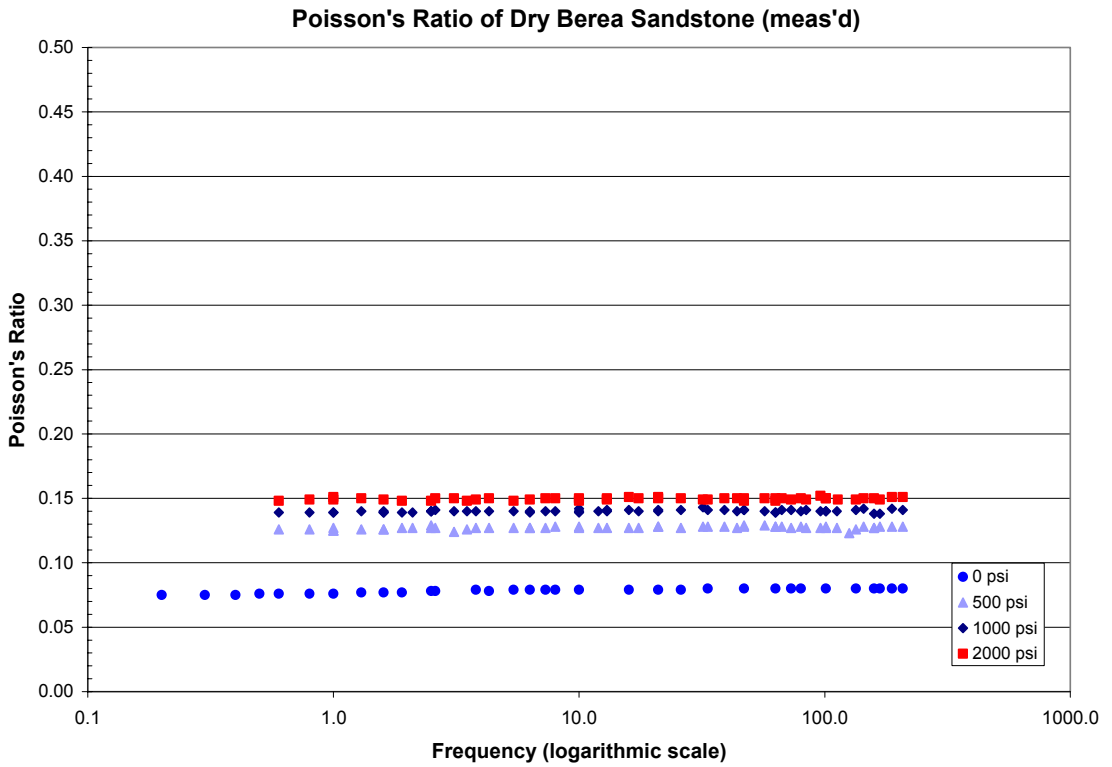

Figure 2. Poisson's ratio of dry Berea sandstone at four confining pressures. 


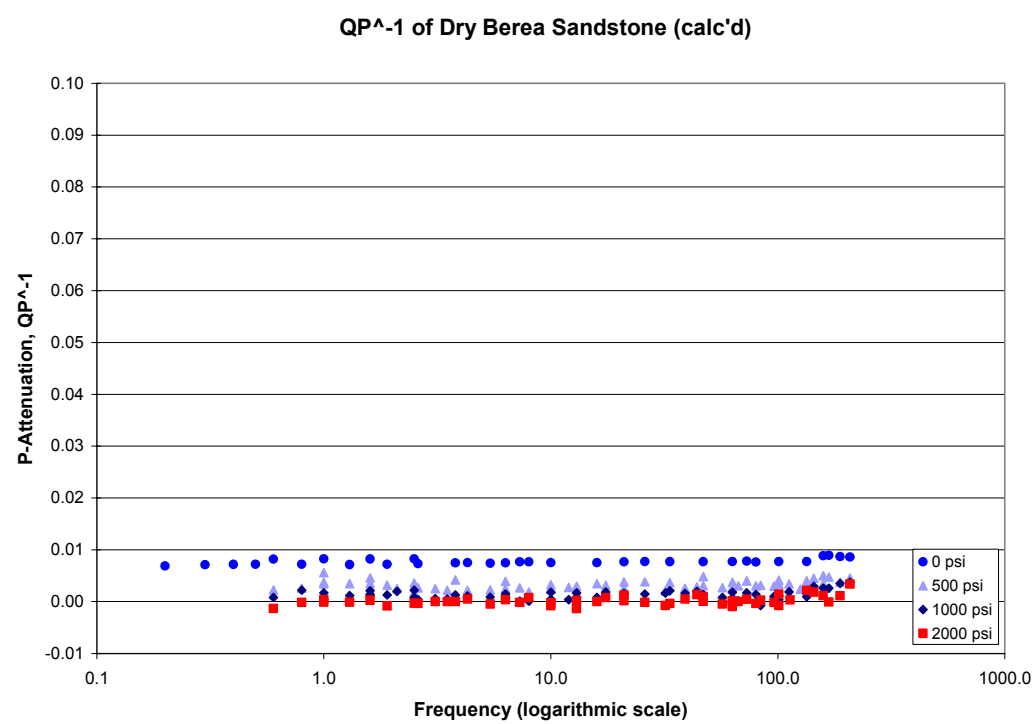

Figure 3. P-wave attenuation in dry Berea sandstone at four confining pressures. Attenuations are calculated from the measurements of two complex moduli.

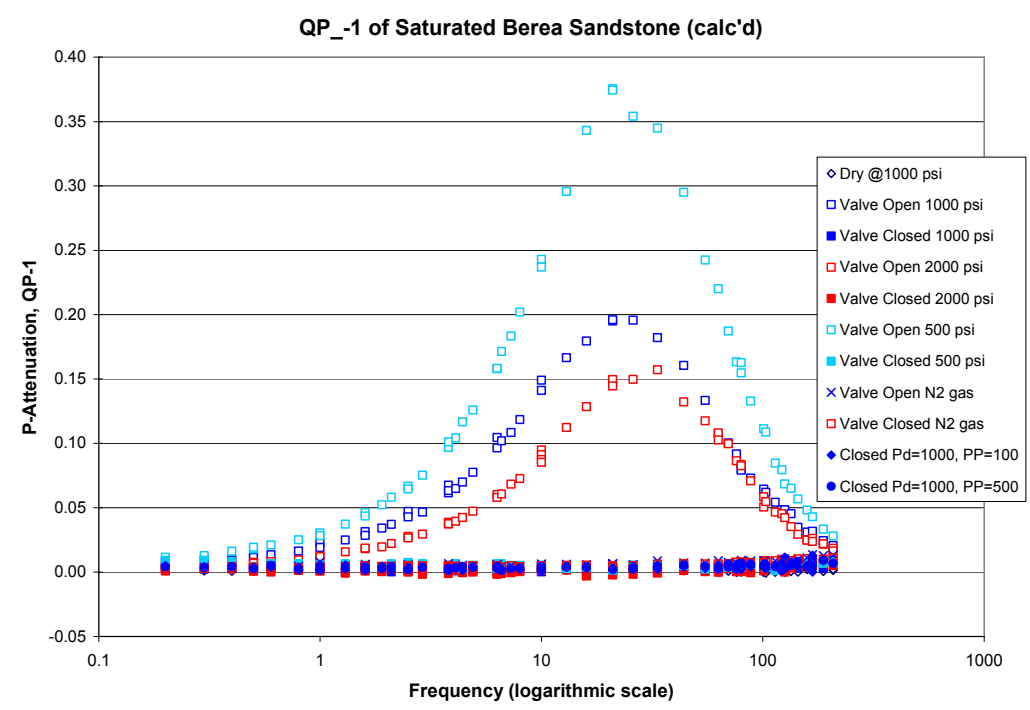

Figure 4. P-wave attenuation in water-saturated Berea sandstone under closed and drained pore-fluid conditions. Large attenuation peak occurs in the openvalve, drained pore-fluid condition due to a bulk relaxation where the dynamic pore fluid pressure is relaxing to a relatively large volume in the valve body. 


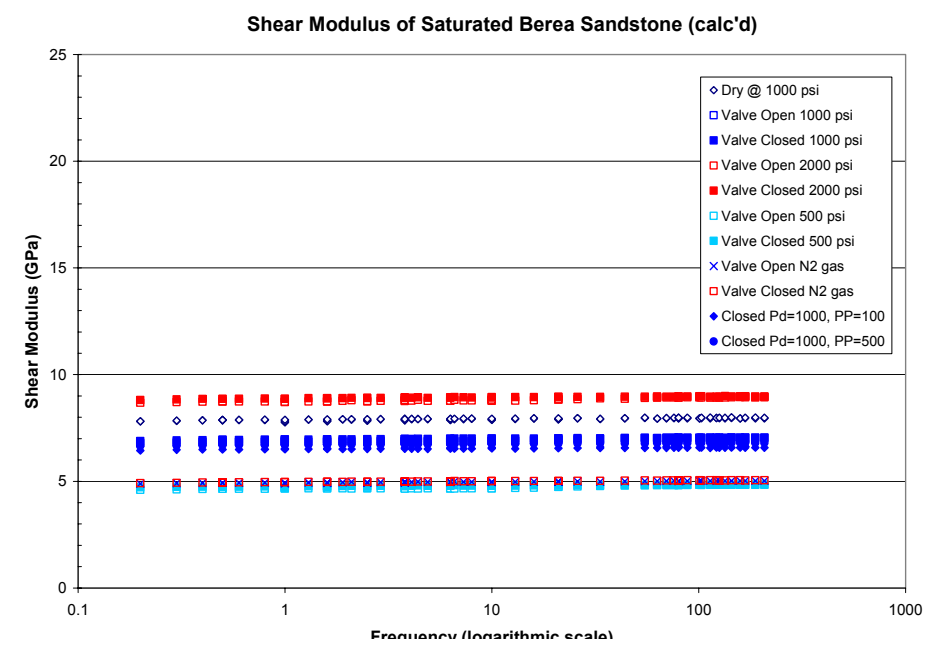

Figure 5. Shear modulus in water-saturated Berea sandstone under closed and drained pore-fluid conditions. Comparison of the dry and water-saturated data at 1000 psi shows there is a water-softening effect. As would be expected, there are negligible differences between the shear moduli under closed and drained pore-fluid conditions.

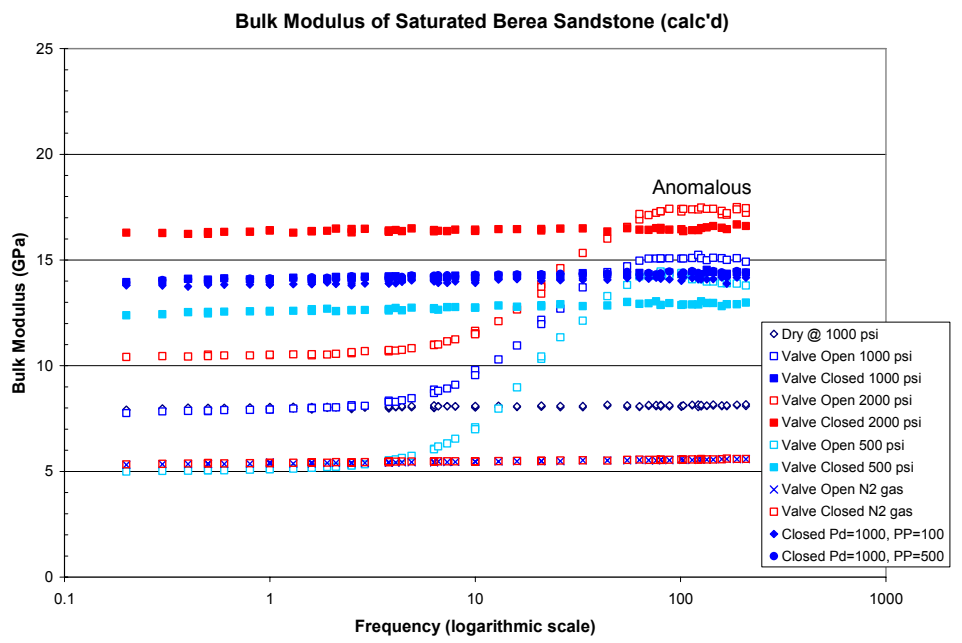

Figure 6. Bulk modulus in water-saturated Berea sandstone under closed and drained pore-fluid conditions. At low frequencies, there is close agreement between the dry frame bulk modulus and the bulk modulus with the pore-fluid valve open. There is anomalous behavior at high frequencies where the drained bulk modulus (valve open) is uniformly larger than the saturated modulus with the valve closed. 


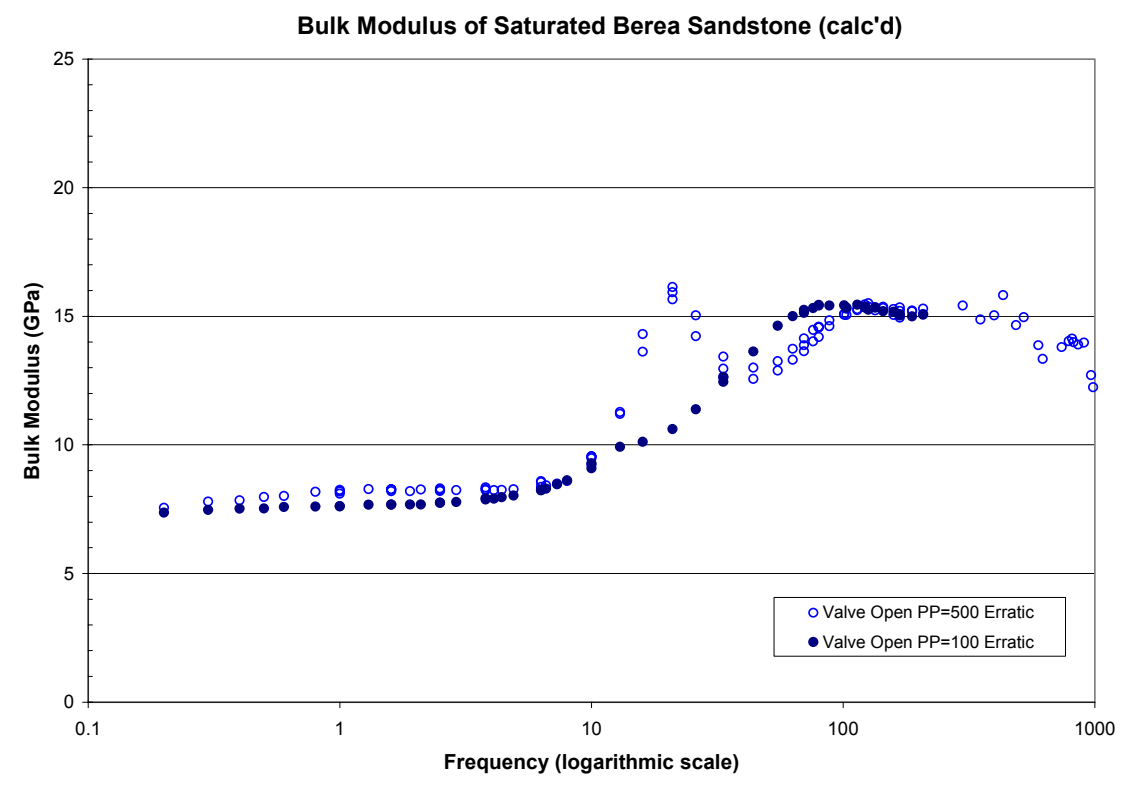

Figure 7. Erratic bulk modulus data measured in water-saturated Berea sandstone with pore fluid valve open, but with different pore fluid pressures. The complicated, frequency-dependent behavior suggests that that a complex resonance and anti-resonance behavior in the pore-fluid valve which is causing the anomalous results in Figure 6. 


\section{Activity at the Colorado School of Mines}

\section{Introduction}

One problem that becomes apparent when making low frequency measurements on some soft samples, is that unrealistic Poisson's ratios $(v)$ are calculated, i.e. greater than 0.5 . The temptation is to attribute these to anisotropy or heterogeneity. In the case of anisotropy, more than one pair of gages is needed to resolve the modulus tensor. On the other hand, heterogeneity can cause unreasonable results due to comparing areas of completely different composition or texture. However, even in materials that should be isotropic and homogeneous, such as a homogeneous glass-like material, the Poisson's ratio can be unreasonable (Figure 8).

\section{Background}

Several reasons can combine to produce these results. In Mechanical testing, it is well known that the sample must be about three times longer than the width to avoid end effects. Our low frequency samples are usually about as wide as long. This is necessary both because many samples arrive much shorter (or broken), or because short samples give better ultrasonic data. Another factor is the mismatch between the end materials (in our case, plastic or epoxy buffers) and the sample. If the modulus of the sample matches that of buffers, the deformations are equal, and end effects vanish. This was one reason why we obtained better data on hard rocks. With our shift to softer rocks and oil sands, this mismatch is amplified. The Poisson's ratio of the sample material is also an issue. If the sample $v$ equals zero, there would be no lateral deformation, and no discrepancy. Such is nearly the case, for example, with dry sandstones $(v=0.1)$. The situation is most extreme for materials with $v$ close to 0.5 , such as liquids or heavy oils.

\section{$\underline{\text { Results }}$}

Schematic representations of the effect are shown in Figures 9 and 10. As a first approximation, the factors that are contributing to the boundary effects can be estimated individually from the raw sample data and dimensions. Ultimately, we can derive a correction to the horizontal data to yield more valid or representative strains

$$
\varepsilon_{H-C O R R E C T E D}=\frac{\varepsilon_{H-M E A S U R E D}}{(1+C)}
$$


The correction term $\mathrm{C}$ will be a combination of the length $(\mathrm{L})$ to radius $(\mathrm{R})$ ratio: $\mathrm{L} / 6 \mathrm{R}$; mismatch between the stiffness of the sample and the buffer: $1-\mathrm{E}_{\mathrm{rx}} / \mathrm{E}_{\mathrm{buf}}$; and the value of the Poisson's ratio itself: $2 v$

$\mathrm{C}=(1-\mathrm{L} / 6 \mathrm{R})\left(1-\mathrm{E}_{\mathrm{rX}} / \mathrm{E}_{\text {buf }}\right)(2 v)$

Often, a multiplicative factor as small as 0.6 must be applied to the lateral strains to account for these end effects. We expect more definitive answers to come form planned finite element modeling of our samples.

To further develop our calibration procedures, finite-element modeling was also performed using a commercially available code. This program, "FEMLAB" is available from $\mathrm{xxxxx}$ and is capable of modeling complex structures composed of a variety of materials. A series of "sandwich" structures is shown in Figure 11. The importance of the length to width ratio in influencing the resulting deformation under uniaxial stress conditions is obvious.

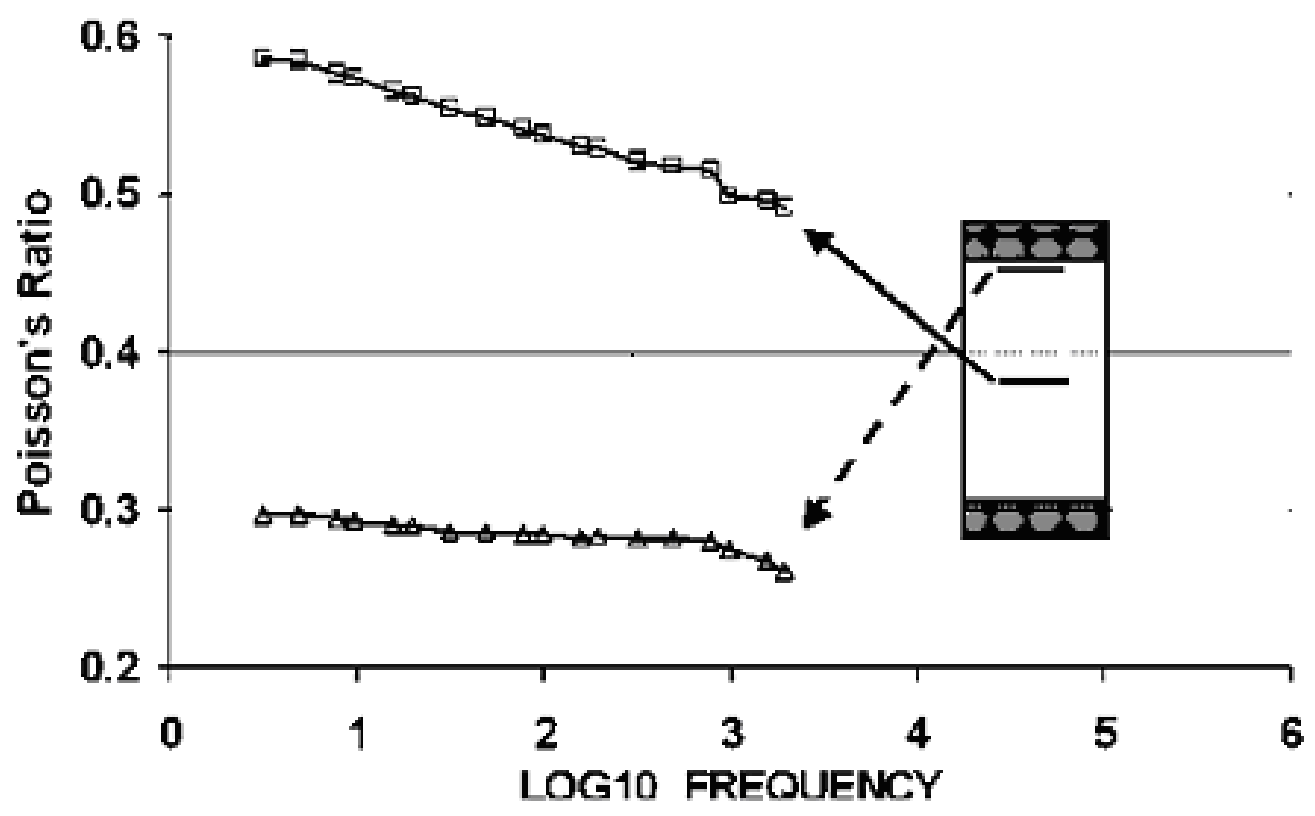

Figure 8. Lateral gages at different locations on a glass-like material completely different values of Poisson's ratio ( $v)$. The gage near the edge gives low values for $v$, and the center gage results in unphysical values for $v$. 
END EFFECTS: Soft or Short Samples
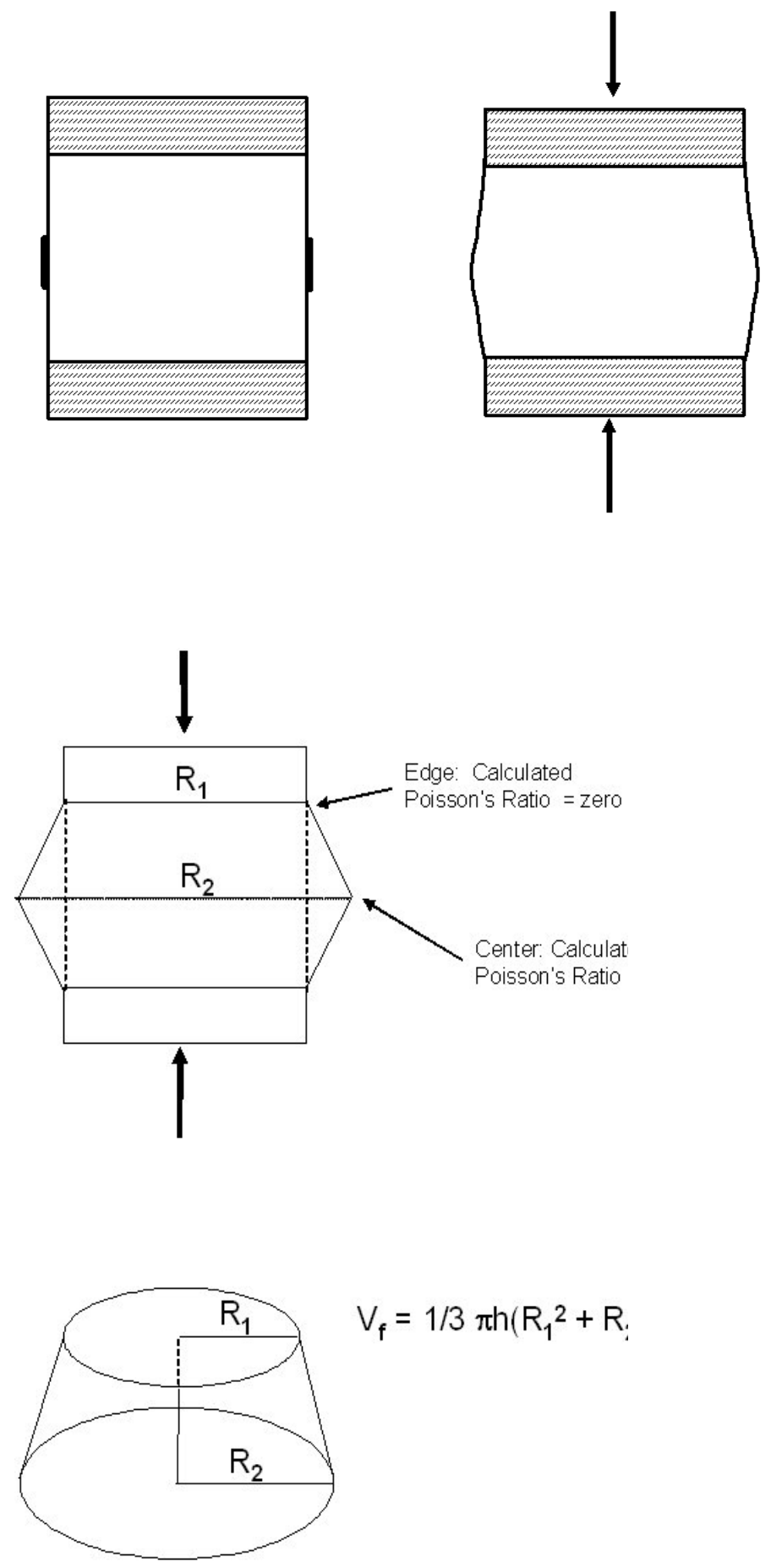

Figure 9.

Schematic of deformation for a short sample with stiff end pieces.
Figure 10. Geometries involved in the deformation of a soft material (Poisson's ratio approximately 0.5 ) with stiff end pieces. To conserve volume, deformation is increased in the center. 

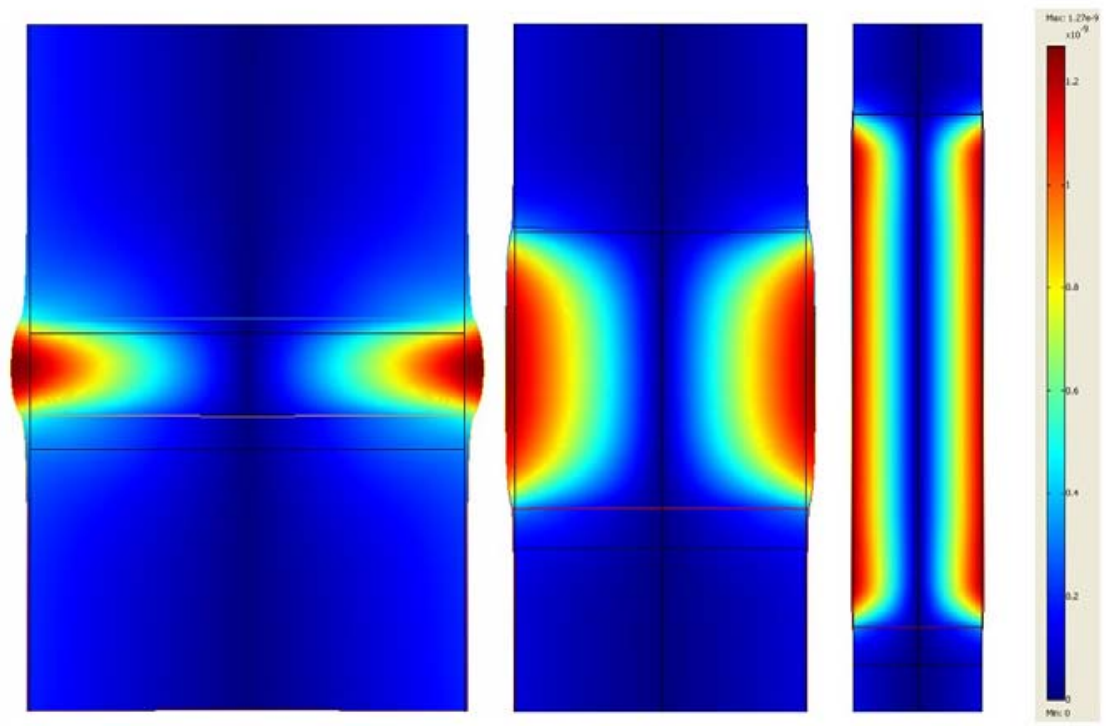

Figure 11. Finite element modeling demonstrates how short samples are influenced by the end effects. 


\section{Activity at Lawrence Berkeley Laboratory}

\section{$\underline{\text { Introduction }}$}

Theoretical modeling of the mechanisms responsible for attenuation are being carried out in concert with the laboratory and field experiments. Such modeling will allow us to understand the factors controlling $1 / \mathrm{Q}$, estimate the magnitude or limiting values of loss under various conditions, and generalize our results to other exploration or reservoir monitoring situations. Here, we concentrate on finite-difference poroelastic models that allows us to investigate the effects of heterogeneities approaching those seen in real rocks.

\section{$\underline{\text { Results }}$}

In a series of papers prior to the present NETL project concerning $\mathrm{Q}^{-1}$ (Pride and Berryman, 2003 a,b; Pride et al., 2004), analytical models for dispersion and attenuation were derived based on-the idea that a porous sample contains one porous phase (e.g., sandy lenses) embedded within another different porous phase (e.g., a shaly sandstone). The idea was that when a seismic wave compresses such a material, the softer phase will respond with a larger change in fluid pressure than the stiffer phase. The resulting fluid pressure gradients are then equilibrated by fluid flow that results in seismic attenuation.

The limitation to two distinct porous phases is quite restrictive. Thus, in the NETL project funded from FY 2005-2006, Steve Pride and a graduate student Yder Masson began developing a finite-difference poroelastic code capable of modeling the attenuation due to arbitrary mesoscale heterogeneity (Figure 12). In a first paper, Masson et al. (2006) present the finite-differencing algorithm that is applied to Biot's (1956) equations of poroelasticity. The model is an explicit time-stepping approach for the velocity and stress fields on a staggered grid. The model is very similar to that of Levander (1988) except that it applies to the poroelastic equations instead of the purely elastic equations. For the first time, a rigorous time-stability condition is analytically derived for the finite-differencing of Biot's equations using fourth-order spatial differences and second-order temporal differences. The accuracy of the scheme is demonstrated by comparing to exact analytical plane-wave solutions of the Biot equations. Several modeling examples are presented. Both 2D and 3D versions of this poroelastic code have been obtained. 


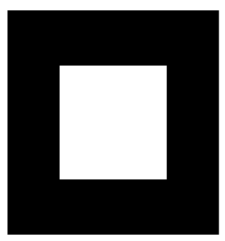

(a)

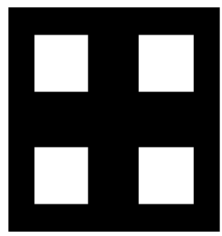

(b)

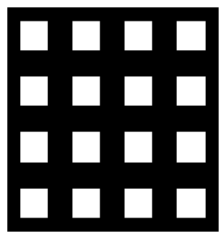

(c)

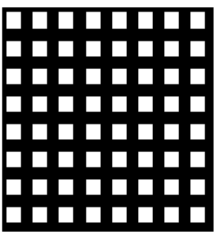

(d)

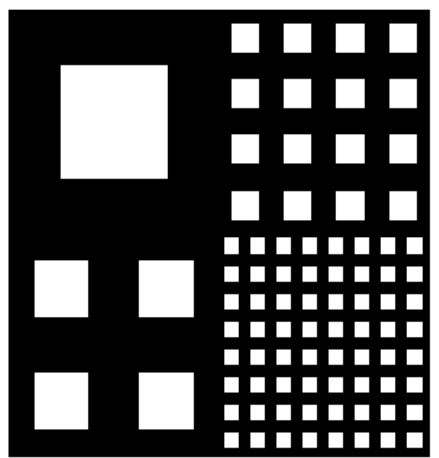

(A)

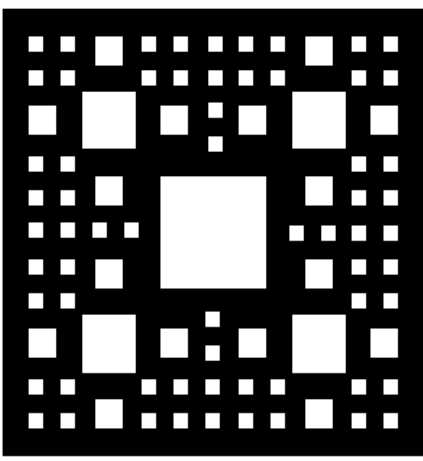

(B)

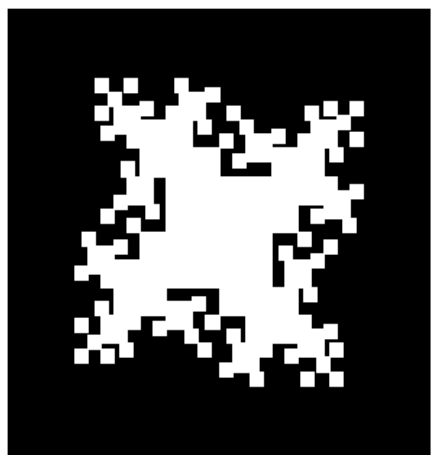

(C)

Figure 12.Geometries of the samples used for testing the double-porosity theory. The sizes of the small and the large samples are $64 \mathrm{~mm}$ and $128 \mathrm{~mm}$ respectively. The sizes of the white squares in (a), (b),(c) and (d) are 32, 16, 8 and 4 millimeters respectively. Each material is made of $1 / 4$ white phase and 3/4 black phase. The three composites (A), (B) and (C) are obtained by mixing together (a), (b), (c) and (d) in different ways.

In the next publication, Masson and Pride (2007) use the code to model attenuation and dispersion in synthetic (computer generated) samples of porous media. The approach is to apply stress to a sample in the form of a step function (stress rate is thus a wide-band pulse) and measure the strain rate of the entire sample. After taking a Fourier transform, the ratio of stress rate to strain rate defines the complex frequency-dependent moduli of the sample from which attenuation in the form of $\mathrm{Q}^{-1}$ can be determined. In these numerical experiments, the analytical double-porosity theory of Pride et al. (2004) is compared to the numerical data. With no free parameters in the analytical model, the fit between the numerical modeling and the theory is quite good (see Figure 13). A range of samples having random mesoscopicscale heterogeneity are then investigated. It is shown both numerically and analytically that the peak value of $\mathrm{Q}^{-1}$ is proportional to the statistical variance of the elastic moduli in the sample. It is also numerically and analytically shown that when there is a gradual transition 
between the various materials present (as opposed to sharp step changes), the high frequency asymptotic behavior is $\mathrm{Q}^{-1}$ proportional to $\omega^{-1}$. Only when the fluid-pressure diffusive skin depth remains large compared to the transition-zone thickness does one obtain the more standard high- frequency asymptote of $\mathrm{Q}^{-1}$ proportional to $\omega^{-1 / 2}$. (e.g., as seen in Figure 13).
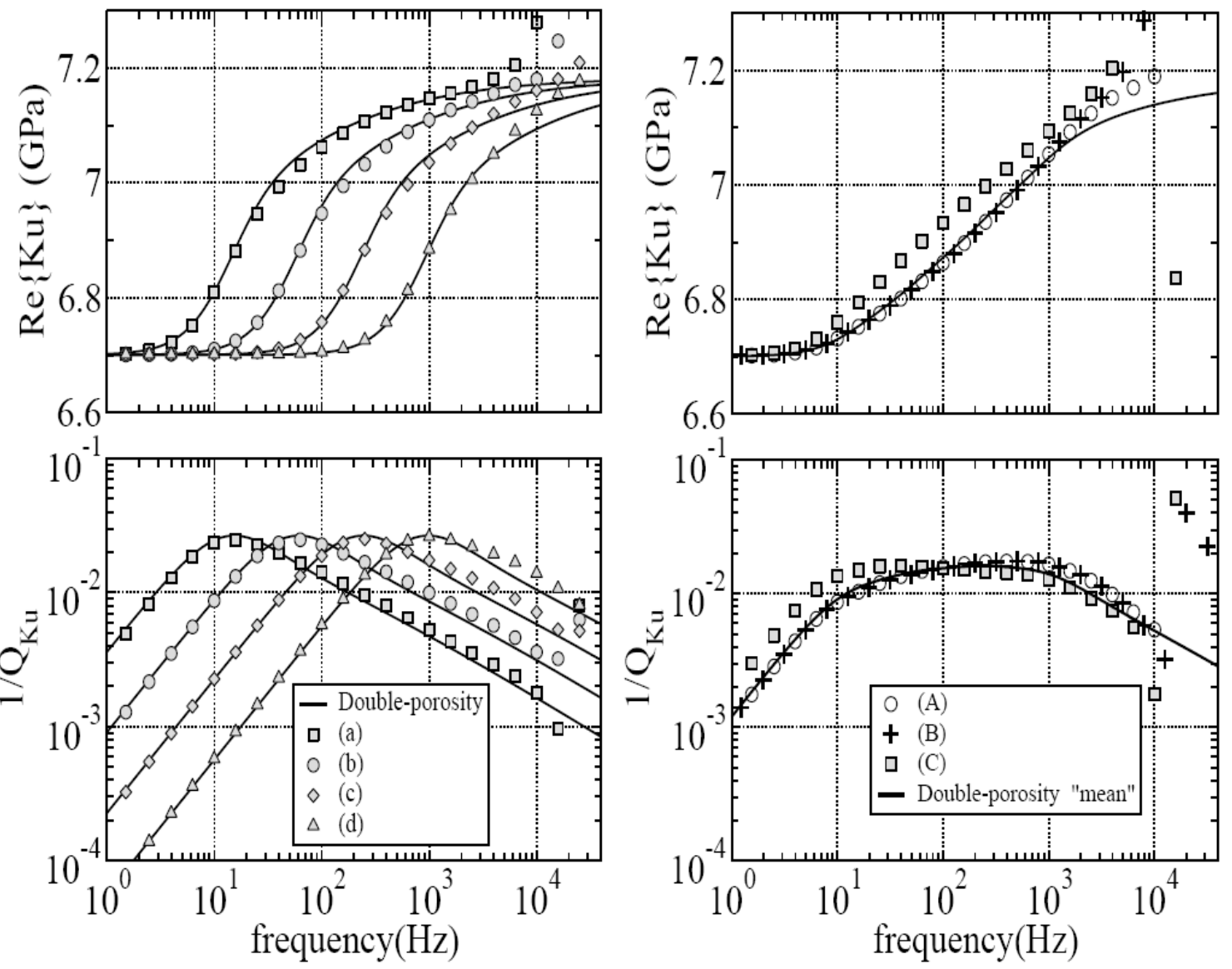

Figure 13: On the left: Real part of the bulk modulus and the respective attenuation obtained from the geometries (a),(b), (c) and (d) in Figure 12. In this example, the black regions in Figure I are filled with the softer/rnore-permeable phase I and the white regions with the stiffer/less-permeable phase 2 . The lines are the predictions of the double-porosity model with no free "fit". parameters. On the right: Real part of the bulk modulus and the associated attenuation obtained from the geometries (A), (B) and (C) in Figure 1. The solid line is a simple mean of the four theoretical curves associated with the samples (a), (b), (c) and (d) given on the left. 

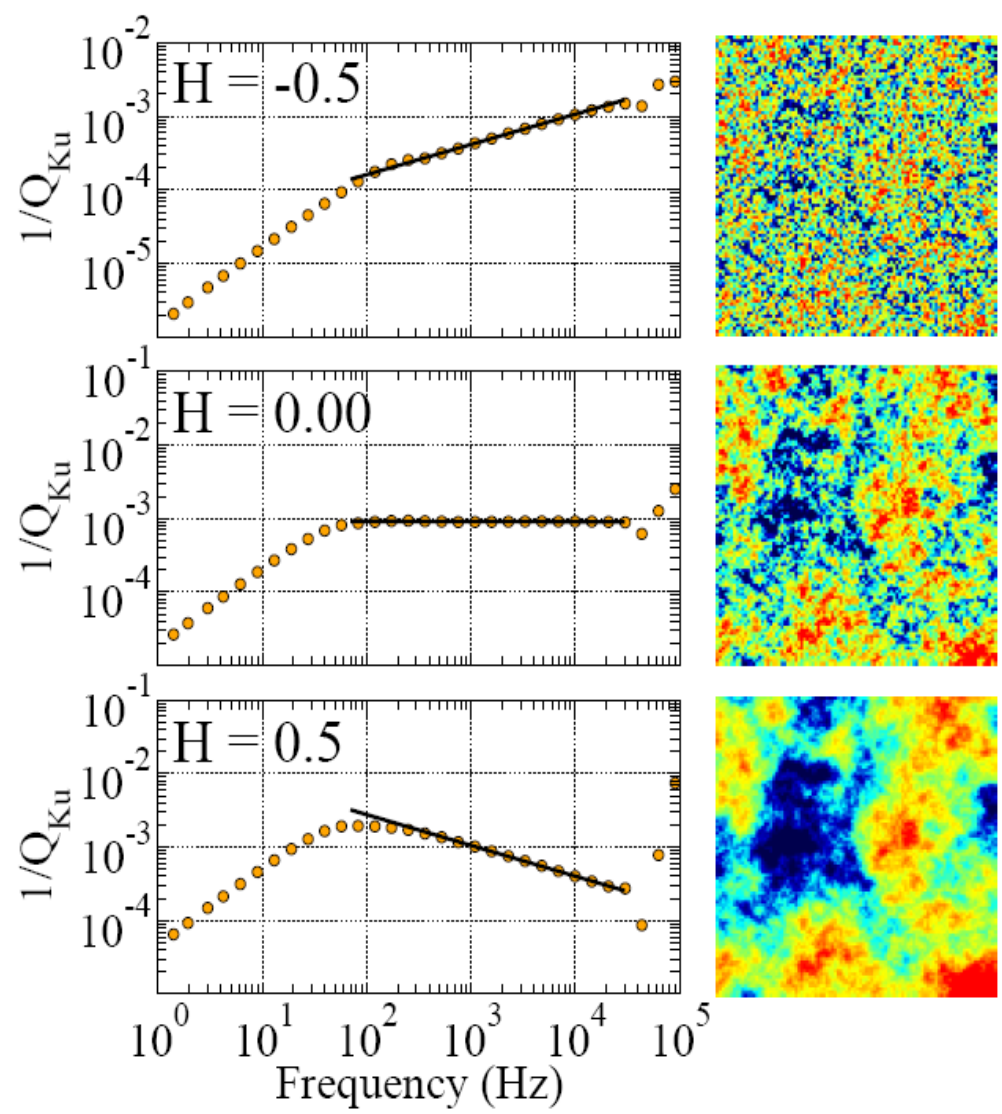

Figure 14: Results of 2D numerical simulations of $\mathrm{Q}_{\mathrm{Ku}}{ }^{-1}(\omega)$ for synthetic samples that have different Hurst exponents $\mathrm{H}$. The symbols are numerical data and the solid line corresponds to $\omega^{-\mathrm{H}}$. To the right are images of the self-affine structure present in the porous-continuum elastic modulus. The subscript $\mathrm{Ku}$ means that it is the dispersion and attenuation associated with the undrained (sealed sample) bulk modulus (isotropic stress/strain) that is being measured. The lowfrequency asymptote $\mathrm{Q}_{\mathrm{Ku}}{ }^{-1} \alpha \mathrm{w}$ corresponds to the band where the diffusive skin depth of the fluid-pressure equilibration is larger than the sample.

Last, Pride and Masson (2006) numerically investigate synthetic materials possessing selfaffine (fractal) scaling of the elastic moduli $\mathrm{M}$ within the sample. Self-affine structure means that the spatial fluctuations $\Delta \mathrm{M}$ of $\mathrm{M}$ vary with scale $\Delta \mathrm{x}$ as $\Delta \mathrm{M}(\mathrm{a} \Delta \mathrm{x}) \alpha \mathrm{a}^{\mathrm{H}} \Delta \mathrm{M}(\Delta \mathrm{X})$ where $\mathrm{H}$ is called the Hurst exponent and a is the scale-chainge factor. It is demonstrated, both numerically and analytically, that the attenuation in such materials has the scaling behavior $\mathrm{Q}^{-1} \alpha \omega^{-\mathrm{H}}$. Negative $\mathrm{H}$ means that the fluctuations in elastic moduli are larger at small scales and smaller at large scales (the likely scenario for most earth materials). An example of these results is given in Figure 14. 


\section{Activity at the University of California, Berkeley}

\section{$\underline{\text { Introduction }}$}

Waves in the earth undergo attenuation, which is caused by scattering due to thin layering and random diffractions and refractions, as well as intrinsic attenuation. O'Doherty and Anstey (1971) derived an approximate relationship between the amplitude spectrum $\mathrm{T}(\omega)$ and the power spectrum $R(\omega)$ of the reflection coefficient series, described by:

$\mathrm{T}(\omega)=\mathrm{e}^{-\mathrm{R}(\omega) \mathrm{t}}$

Apart from multiple scattering which can be modeled with 1D random structures, additional scattering attenuation occurs due to multiple backscattering and random diffraction and refraction, which can be captured in 3D modeling of inhomogeneous media (Muller and Shapiro, 2004). Inelastic intrinsic attenuation can be explained using single or multiple superposed relaxation mechanisms. What remains an open challenge is the ability to distinguish between scattering and intrinsic attenuation.

In this study, we model the Earth assuming no lateral heterogeneity, and calculate the attenuation due to scattering with a 2D model. To fully capture the effect of scattering attenuation, we would need to account for the lateral heterogeneities as well as compute elastic wave propagation for a 3D model. In this sense, we expect that our estimate of the scattering attenuation is underestimated relative to a fully heterogeneous 3D model, however, we use this estimate to quantify the approximate attenuation that is intrinsic.

\section{$\underline{\text { Data Acquisition }}$}

We installed a down-hole 3-component geophone array with 12 levels at $10 \mathrm{ft}$ spacing, with the bottom level at $140 \mathrm{ft}$ depth. The well is located in the SE corner of the LLNL facility and has a PVC casing of 5', diameter. The groundwater at this location is at $160 \mathrm{ft}$. We grouted the geophones with a cement-bentonite mix, in an effort to suppress tube waves and improve coupling. In July 2006, we collected multiple offset shot points at multiple azimuths around the well, using an elastic wave generator source.

\section{$\underline{\text { Analysis }}$}

We looked at the zero-offset data (Figure 15), and aligned the direct arrival at the first-break time. We computed the amplitudes for a 10 millisecond window around the first-break time, after correcting for spherical divergence. 
From the direct wave arrival time, we determined a rough velocity profile which we further modeled into a $1 \mathrm{ft}$ resolution profile for the velocities, and density, based on the natural gamma $\log$ and $\log$ descriptions that were available for this well. We generated synthetics using a $4^{\text {th }}$ order space, $2^{\text {nd }}$ order time, $2 \mathrm{D}$ finite difference elastic model. For the synthetic data, we applied a $1 / \sqrt{ } \mathrm{r}$ spherical divergence correction and looked at the amplitudes of the zero-offset. We corrected the amplitudes of the real and synthetic data by the square root of the local impedance.

\section{Q Estimates}

Figure 16 shows the reflection coefficient series that were used to compute the synthetic data. The root mean square reflectivity is 0.059 . Figure 17 shows the amplitudes versus wavenumber of the synthetic and real data, after corrections for spherical divergence and local impedance. We plotted the ODA curve for the power spectrum, which was equal to 0.013. The ODA curve fits the modeled data fairly well, however when compared to the real data, there exists a pronounced drop in amplitude within the first two wavelengths which is not captured by the ODA and synthetic amplitude versus wavelength relationship. We therefore concluded that the main attenuation mechanism within the shallowest regions is controlled by intrinsic rather than scattering attenuation. As mentioned before, another factor which may cause the amplitudes of the synthetics to differ from the real data, though it may be of secondary importance, is the lack of lateral heterogeneity and 3D modeling of scattering.

Figure 17 also shows three curves plotted over the real data that aim to capture the Q factor as a function of depth. Using these proposed curves, we provide an approximate estimate for the Q factor, which is in the order of 1 to 2 above $60 \mathrm{ft}, 2$ to 7 between 60 and $100 \mathrm{ft}$, and 1217 between 100 and $160 \mathrm{ft}$. The estimated Q factors are very low, which for this site was expected, as a former surface seismic experiment conducted by the authors showed absence of even shallow reflectors which can be accounted for by the extremely low Q in the near surface.

\section{$\underline{\text { Conclusion }}$}

We analyzed the amplitudes of the direct arrival from zero-offset VSP data from a permanent down-hole geophone array in a well in LLNL. We used the gamma log and interval velocities to model the density and velocity of the subsurface assuming no lateral heterogeneity and computed synthetic zero-offset data in a 2D finite difference elastic model. We compared the amplitudes of the zero-offset synthetics to the predicted amplitudes based on the ODA formula, and found that they were in good agreement. We compared the scaled amplitudes of the synthetic data to the real data in order to determine what factor of $\mathrm{Q}$ is due to intrinsic attenuation. We found a very low $\mathrm{Q}$ factor in the upper $60 \mathrm{ft}$ ranging from 1 to 2 , which is primarily due to intrinsic attenuation, and an increasing $\mathrm{Q}$ factor with depth, up to 12 to 17 at a depth greater than $100 \mathrm{ft}$, which is equally dependent on scattering and intrinsic attenuation. 


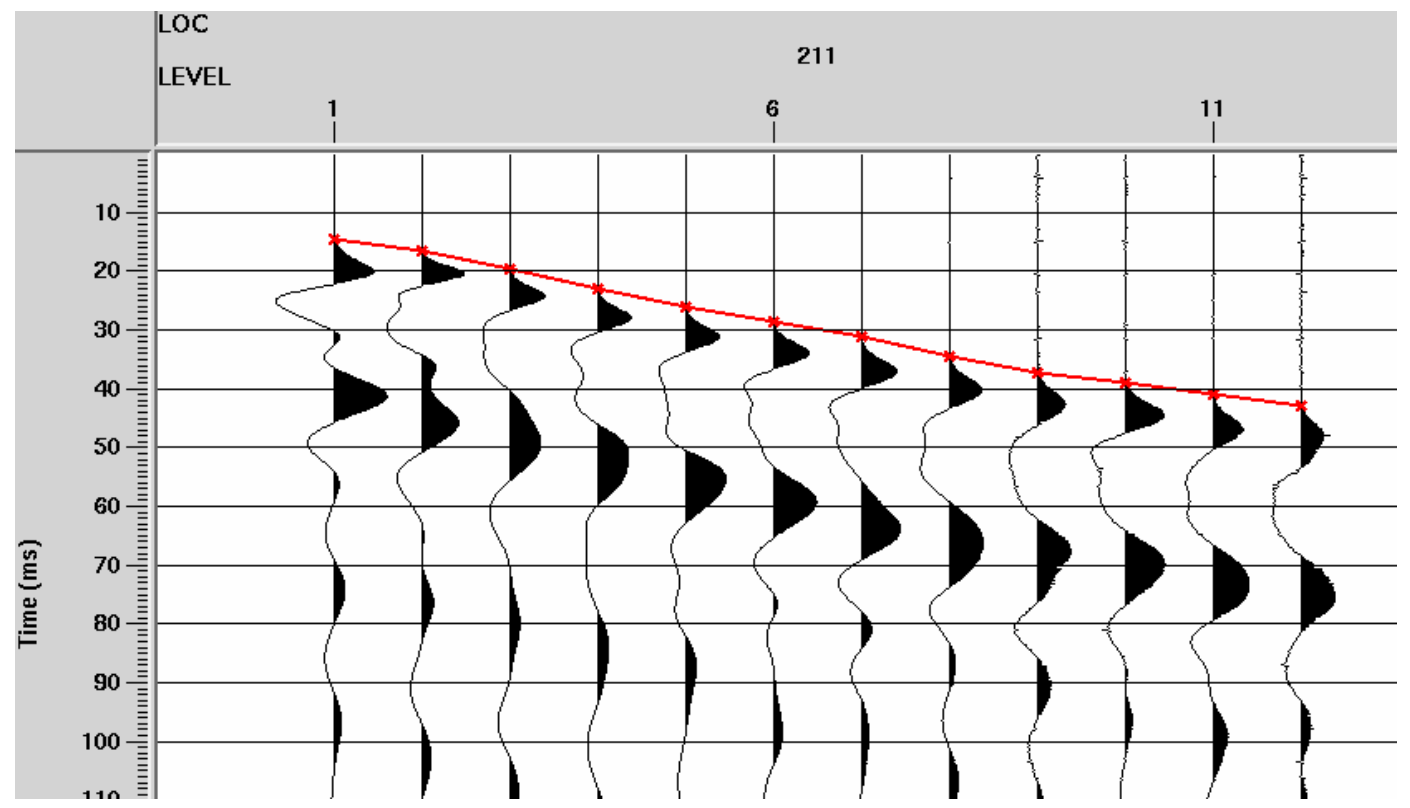

Figure 15: Zero-offset data with first-break pick.

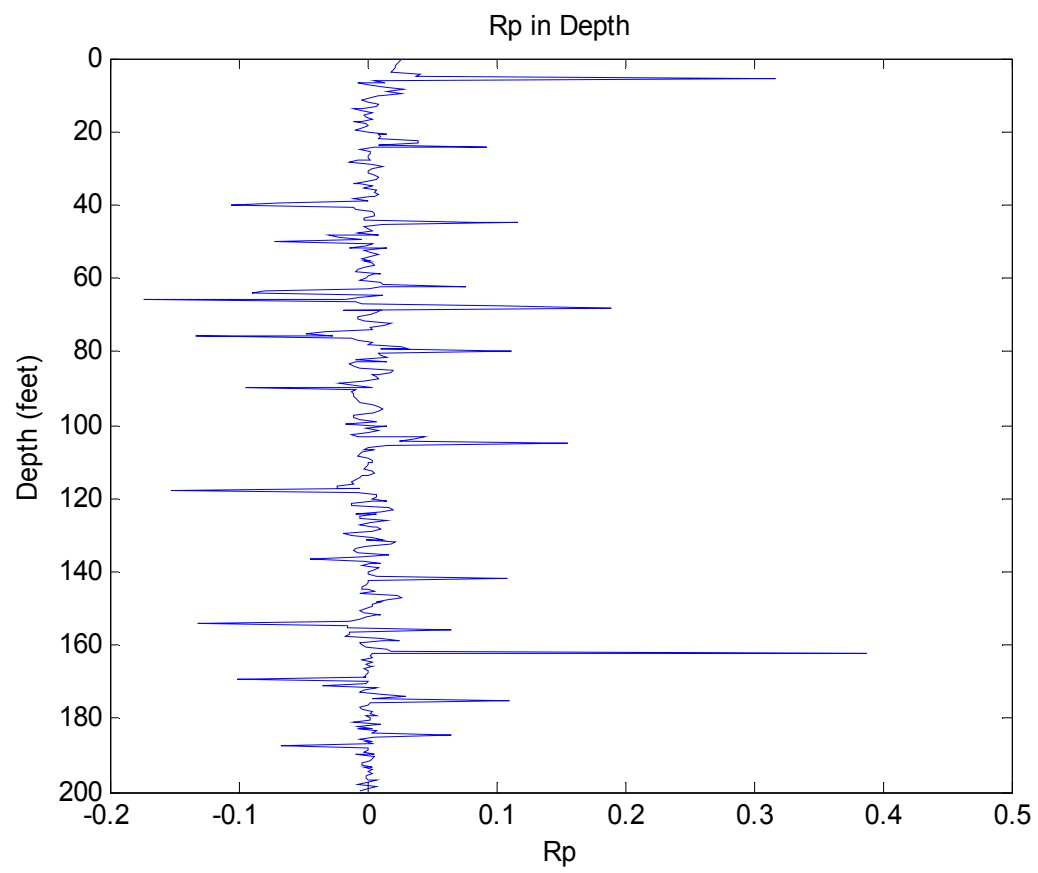

Figure 16:

The reflection coefficient series $(\mathrm{Rp})$ 


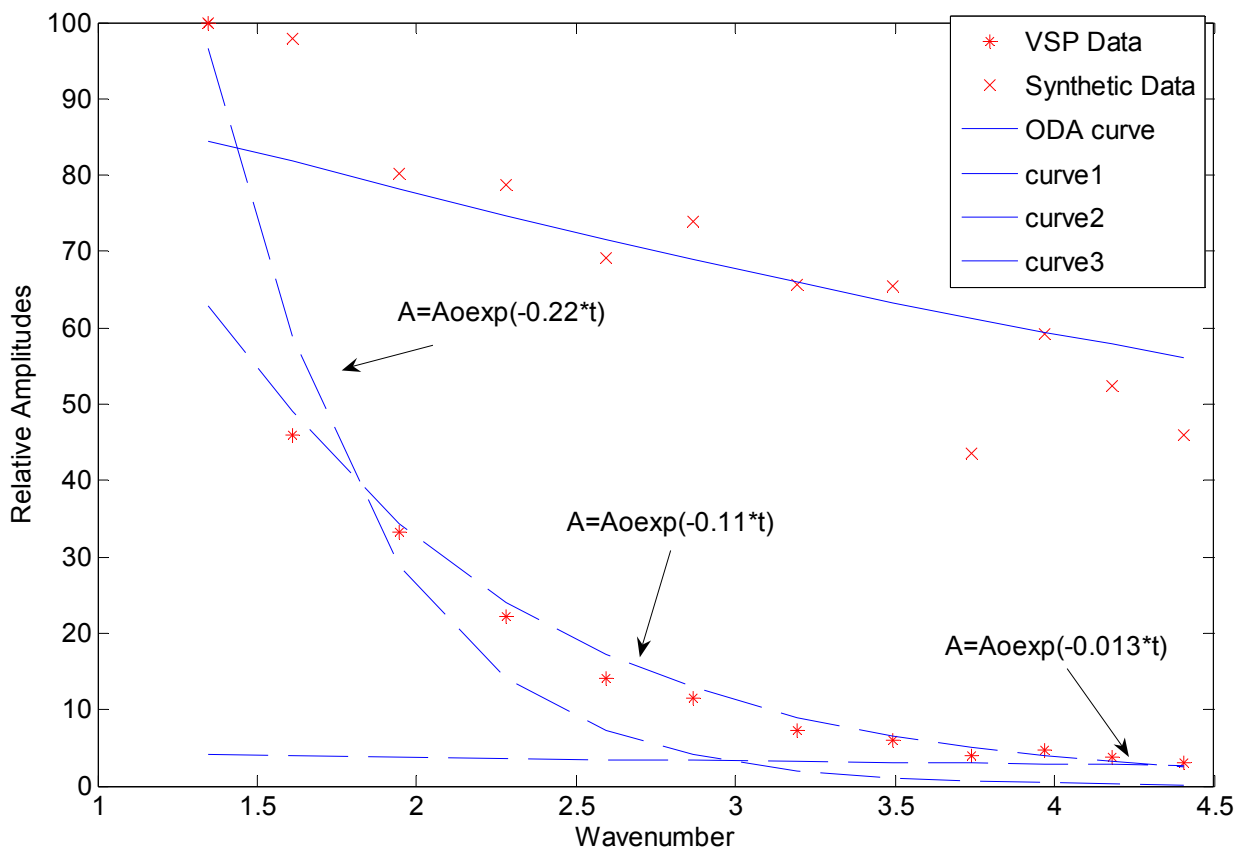

Figure 17: Relative amplitudes of synthetic and real data, after corrections for spherical divergence and local impedance. 


\section{Conclusions and Plans}

The plans for the next budget period (2007) primarily are to perform research on the samples and data in hand, and obtain additional data sets. We currently have enough material to start extensive research combining rock, fluid, log, and seismic data.

- Additional finite difference models will be run based on rock texture measurements

- Model results will be compared to laboratory measurements

- Obtain spectral dependence of intrinsic 1/Q component from VSP

- Measure angle-dependent intrinsic and scattering attenuation

- Relate to reflection data at Genesis Field

-Finalize sets of base functions for dispersion and attenuation in sandstones and sands as

A function of porosity and controlled partial saturation.

- Complete measurements of twin samples obtaining cross-calibration between CSM and

ChevronTexaco's devices

- Review and test measurement methodologies.

- Search through seismic data typical of deepwater exploration and/or 4D studies in deepwater sediments to find conditions of dispersion in amplitudes.

- Develop log expression of shear and compressional velocity, velocity dispersion, and attenuation.

- Numerous papers and presentations are under preparation

Each of the participating institutions will focus on their particular strengths, but these efforts are not independent. The research of any one group will depend upon, and integrate, the results of the other groups.

Schedule:

We expect to be near completion of the project by December 31, 2007, although collecting laboratory data and analyzing field data often do not go strictly according to schedule. 


\section{References}

Adam, L., Batzle, M. and Brevik, I., 2006, Gassmann's fluid substitution and shear modulus variability in carbonates at laboratory seismic and ultrasonic frquencies, Geophysics, 71, F173-F183.

Batzle, M., Hoffmann, R., Prasad, M., Kumar, G., Duranti, L. and Han, D.H., 2005, Seismic attenuation: observations and mechanisms, SEG Technical Program Expanded Abstracts, 1565-1568.

Biot, M. A., Theory of propagation of elastic waves in a fluid-saturated porous solid. 1. Lowfrequency range, J. Acoust. Soc. Am., 28, 168-178, 1956.

Dunn, K. J., Sample boundary effect in acoustic attenuation of fluid-saturated porous cylinders, 1987, J. Acoust. Soc. Am., 81, 1259-1266.

Levander, A. R., Fourth-order finite-difference P-SV seismogram, Geophysics, 58, 14251436, 1988.

Masson, Y., and S. R. Pride, Poroelastic finite-difference modeling of seismic attenuation and dis- persion due to mesoscopic-scale heterogeneity, J. Geophys. Res., 112, to appear February/March, 2007.

Masson, Y., S. R. Pride, and K. Nihei, Finite difference modeling of Biot's poroelastic equations at seismic frequencies, J. Geophys. Res., 111, BIO,305, 2006.

Pride, S. R., and J. G. Berryman, Linear dynamics of double-porosity and dual-permeability materials. 1. Governing equations and acoustic attenuation, Phys. Rev. E, 68, 036603, 2003 a.

Pride, S. R., and J. C. Berryman, Linear dynamics of double-porosity and dual-permeability materials. 11. Fluid transport equations, Phys. Rev. E, 68, 036604, 2003 b.

Pride, S. R., and Y. J. Masson, Acoustic attenuation in self-affine porous structures, Phys. Rev. Lett., 97, 184,301, 2006.

Pride, S. R., J. C. Berryman, and J. M. Harris, Seismic attenuation due to wave-induced flow, J. Geophys. Res., 109, B01201,doi:10.1029/2003JB002639, 2004.

Spencer, J.W., 1981, Stress relaxations at low frequencies in fluid saturated rocks: attenuation and modulus dispersion, J. Geophys. Res., 86, 1803-1812. 
Spencer, J. W., Cates, M. E. and Thompson, D. D., 1994, Frame moduli of unconsolidated sands and sandstones, Geophysics, 59, 1352-1361.

White, J. E., 1985, Biot-Gardner theory of extensional waves in porous rods, Geophysics, 51, 742-745. 